\title{
Management and treatment of HIV: are primary care clinicians prepared for their new role?
}

\author{
Sampath Wijesinghe ${ }^{1,2^{*}}$ and Jeffrey L. Alexander ${ }^{1}$
}

\begin{abstract}
Background: Current literature suggests the number of HIV clinicians in the United States is diminishing. There are 294,834 primary care providers (PCP) in the United States, and, of these, 3101 provide care to HIV-positive patients. More PCPs to treat and manage HIV patients may be the solution to alleviate the HIV provider shortage. However, PCPs also face challenges, including workforce shortages. We surveyed PCPs to determine perceived barriers, beliefs, and attitudes about their readiness to manage and treat HIV patients.
\end{abstract}

Methods: Following a quantitative, descriptive, cross-sectional survey design, currently practicing clinicians in primary care (physicians, residents, physician assistants, family nurse practitioners) were emailed a link to the study survey. Three hundred forty-seven family medicine clinicians from 47 states met the study inclusion criteria.

Results: Most $(245 / 347,70.6 \%)$ of the PCPs agreed that PCPs should take care of HIV patients. PCPs practicing HIV medicine $(n=171)$ were more likely than those not practicing HIV medicine $(n=176)$ to agree that PCPs should help with the HIV provider shortage $(U=10,384, p<0.001)$ and that PCPS are the best solution to the HIV provider shortage $(U=10,294, p<0.001)$. The majority $(206,59.4 \%)$ believed PCPs are the best solution for the HIV provider shortage. Of 133 physician assistants (PAs) and family nurse practitioners (NPs), seventy (52.6\%) believed they could be ready to manage HIV patients with some training.

Conclusion: The HIV provider shortage in the United States is likely to continue. To alleviate the provider shortage, PCPs should be offered additional training, decreased workload, and increased compensation when treating and managing HIV patients. Also, encouraging PAs and family NPs to be involved with HIV medicine may be a solution.

Keywords: HIV, Primary care, Primary care providers, HIV provider shortage, Primary care workforce shortage, Challenges with HIV disease

\section{Background}

Nearly 1.1 million persons in the United States (US) are living with HIV, and approximately $14 \%$ of them are unaware of their HIV-positive status [1]. The number of new HIV diagnoses annually has remained stable; 37,832 new HIV cases were diagnosed in 2018 [1]. While

\footnotetext{
* Correspondence: samwije@stanford.edu

${ }^{1}$ College of Graduate Health Studies, A. T. Still University, 5850 East Still Circle, Mesa, AZ 85206, USA

${ }^{2}$ MSPA Education, Stanford School of Medicine, 1265 Welch Rd., Ste. 100,

Stanford, CA 94305-5408, USA
}

African-American homosexual men had the highest number of newly-diagnosed cases in 2018, a substantial increase was noted in Hispanic/Latino gay or bisexual men [1]. Overall, there have been 650,000 deaths from the AIDS epidemic [2]. Antiretroviral therapy (ART) is frequently recommended for HIV patients, because it stabilizes their immunity and helps them live longer and healthier lives [3]. However, ART is not a cure [3]. HIVpositive patients will continue to need sufficient number of HIV providers as the number of new infections

(c) The Author(s). 2020 Open Access This article is licensed under a Creative Commons Attribution 4.0 International License, which permits use, sharing, adaptation, distribution and reproduction in any medium or format, as long as you give appropriate credit to the original author(s) and the source, provide a link to the Creative Commons licence, and indicate if changes were made. The images or other third party material in this article are included in the article's Creative Commons licence, unless indicated otherwise in a credit line to the material. If material is not included in the article's Creative Commons licence and your intended use is not permitted by statutory regulation or exceeds the permitted use, you will need to obtain permission directly from the copyright holder. To view a copy of this licence, visit http://creativecommons.org/licenses/by/4.0/ The Creative Commons Public Domain Dedication waiver (http://creativecommons.org/publicdomain/zero/1.0/) applies to the data made available in this article, unless otherwise stated in a credit line to the data. 
continues and others who were previously diagnosed live longer.

According to the American Academy of HIV Medicine (AAHIVM) [4], over 32\% of existing HIV clinicians will stop practicing HIV medicine over the next 10 years. More recently, Sweet [5] suggested that approximately $50 \%$ of HIV clinicians could retire in the next $5-10$ years. Gatty [6] suggested that the reduction of HIV clinicians has already begun. A national survey of program directors of the Ryan White HIV/AIDS Program indicated a lack of qualified clinicians and poor reimbursement for HIV care are the primary challenges for recruitment of HIV clinicians [7]. The Mathematica Policy Research organization investigated the HIV provider shortage in 2016 and concluded that provider shortage increased from 7 to $30 \%$ between 2010 and 2015 [8]. The organization further concluded "we have a reason to believe this trend is continuing and will likely have long-term adverse consequences for public health if not addressed" [8]. While the number of HIV providers is decreasing, the number of individuals with HIV is increasing because of new HIV infections and greater HIV survival rates due to advanced ART [9]; therefore, it appears that primary care providers (PCPs) may need to help care for people living with HIV.

Research suggests the best approach to manage HIV patients involves a multidisciplinary team of HIV specialists, primary care physicians, family nurse practitioners (NPs), and physician assistants (PAs) [10]. Family NPs and PAs are useful additions to the team, because they combine quality HIV care with cost-effectiveness [11]. Researchers $[12,13]$ have found that teams of physicians, family NPs, and PAs achieve similar outcomes for HIV patients compared with physicians alone. Consequently, these teams of physicians, family NPs, and PAs could function as PCPs that effectively administer collaborative, interprofessional care for HIV patients.

Although primary care physicians can and do treat HIV patients [14], research findings suggest the primary care workforce will also experience a shortage of providers [15]. Other barriers that may keep PCPs from initiating HIV management and treatment are payment for medical services, government mandates, time, staffing and training, and work-life balance [16]. Even though the increased engagement of PCPs in the management and treatment of HIV patients may improve overall access to and quality of HIV care [17], little research has investigated whether PCPs are willing and prepared to manage and treat HIV patients. Therefore, the current study surveyed PCPs to determine perceived knowledge, beliefs, and attitudes about their readiness to manage and treat HIV patients.

\section{Methods}

The current study used an anonymous, quantitative, descriptive, cross-sectional survey design. Convenience sampling was used to recruit potential participants. Study participants included US clinicians in primary care (physician, resident, PA, or family NP) currently practicing in a part-time or full-time capacity. Participants were located through primary care state and national associations, AAHIVM, universities, health systems, and social media networks (LinkedIn and Facebook). Clinicians who practiced in other fields (internal medicine, gynecology, sole pediatrics, or other) and students were excluded from participation. The local institutional review board considered the current study exempt from review.

\section{Survey development}

Existing standardized survey instruments did not meet our preferred criteria for the current study; therefore, an online survey was created using SurveyMonkey (San Mateo, CA) (Appendix). The survey was developed specifically to evaluate the perceptions of PCPs regarding their knowledge, beliefs, and attitudes about their readiness to manage and treat HIV patients. Face and content validity were established through collaboration between the primary researcher and colleagues in family medicine. The colleagues evaluated the survey questions and provided constructive feedback to improve the validity. The survey was revised, and then sent to three family medicine clinicians to re-evaluate its content validity. With their additional feedback, the final survey was designed.

The survey included 36 closed-ended items and four key sections: demographics, knowledge, beliefs, and attitudes (Appendix). The demographics section included 15 items related to profession designation, area of practice, number of weekly hours in primary care, gender, age, number of years in practice, plans to retire, race/ethnicity, state of practice, practice location, practice setting, number of patients treated per day, if currently treating HIV patients in practice, number of HIV patients treated in practice (if applicable), and if the participant was a certified HIV specialist. Knowledge items used a three-point, Likert-like scale (yes, no, uncertain). Beliefs and attitudes items used a fivepoint Likert scale (strongly agree, agree, uncertain, disagree, and strongly disagree). An area for written comments was also provided at the end of the survey. The survey took about $10 \mathrm{~min}$ to complete.

\section{Data collection}

Three emails were sent during the study. An initial email was sent to all potential study participants indicating they would be receiving the survey. At the same time, other entities (i.e., family medicine residency programs and health care systems) were contacted by email to ask for their help in reaching out to potential study participants. An email invitation with a link to the online survey was sent. By clicking on the link, participants were informed that they were providing consent to participate in the study. After 6 
weeks, an email reminder was distributed. The survey was open for 3 months. As an incentive to participate, a raffle for a \$25 Starbucks gift card was included at the end of the survey. Participants provided their email address to enter the raffle and were informed their email address would not be linked to their survey responses.

\section{Statistical analysis}

Data collected were analyzed using IBM SPSS version 24.0 (Armonk, NY: IBM Corp.) statistical software. Incomplete surveys were excluded from analysis. Descriptive statistics were calculated for all variables using frequencies and percentages for categorical data and means and standard deviations (SDs) for continuous data. The Likert scale items were converted to a 3-point response scale (agree, uncertain, or disagree) prior to analysis. Not applicable answer choices in the survey were grouped under the uncertain category. Summary statistics were also calculated for subgroups of PCPs. Specifically, we summarized survey responses for beliefs and attitudes for all PCPs, only PCPs who indicated they were involved with HIV medicine, only PCPs who indicated they were not involved with HIV medicine, and only PAs and family NPs. The Kolmogorov-Smirnov Test of Normality was used to examine the distribution of the data, which revealed the data were not normally distributed $(p<.05)$. Mann-Whitney $\mathrm{U}$ analysis was used to compare two survey items between PCPs who reported currently treating HIV patients and those who reported not currently treating HIV patients. The two survey items for comparison were related to whether PCPs should take care of HIV patients and if PCPs are the best solution to the HIV provider shortage. Significance was set a priori at $p<.05$, two-tailed.

\section{Results}

Three hundred eighty-five PCPs from 47 US states responded to the survey. Of those, 347 surveys were included in the analyses; 38 surveys were excluded, because seven were incomplete, four were completed by PCPs in unrelated careers, and 27 were from different specialties.

\section{Demographic characteristics}

Most respondents were female $(202,58.5 \%)$ and White (203, 58.5\%) (Table 1). The mean (SD) age was 43.2 (11.9) years, mean number of hours worked weekly was 39.3 (15.5) hours, and mean number of years in practice was 12.2 (10.8) years. Most respondents (172, 49.6\%) were physicians who worked fulltime $(258,74.4 \%)$. Two hundred ninety-nine $(86.2 \%)$ consulted 10 patients or more in a day. Most $(160,46.1 \%)$ anticipated working more than 10 years, and most $(101,29.1 \%)$ resided in California. Diverse practice locations and practice settings were reported. One hundred seventy-one (49.3\%) reported currently treating HIV patients.

\section{Knowledge}

Most PCPs had adequate knowledge about the management and treatment of HIV patients (Table 2). Although the majority $(186,53.6 \%)$ knew the number of new HIV diagnosis every year, 161 (46.4\%) did not know or were uncertain.

\section{Beliefs}

Respondents' beliefs are summarized in Table 3. Most PCPs $(152,43.8 \%)$ reported they did not have clinical knowledge to manage and treat HIV patients. Two-hundred seven (59.7\%) were ready to take care of HIV patients with some training, and most $(245,70.6 \%)$ agreed PCPs should take care of HIV patients. When asked about compensation, 183 (52.7\%) of PCPs were uncertain, and 138 (39.8\%) believed HIV providers were not compensated sufficiently.

\section{Attitudes}

Respondents' attitudes are summarized in Table 4. More than half $(193,55.6 \%)$ of PCPs worried about the projected HIV workforce shortage. The majority $(239,68.9 \%)$ indicated they would like to treat HIV patients while providing primary care. Most (291, 83.8\%) believed helping was important to alleviate the HIV provider shortage. One-hundred fifty-nine (45.9\%) were not interested in attending salaried, HIV-specialist fellowship training, but over half $(209,60.2 \%)$ were interested in treating HIV patients if time permitted. Over half $(179,51.6 \%, n=179)$ were also interested in treating HIV patients if they were compensated better, and most (206, 59.4\%) believed PCPs were the best solution for the HIV provider shortage.

\section{Responses from PCPs not involved with HIV medicine}

Of the 347 study participants, 176 PCPs were not involved with HIV medicine. Of these, most (120, 68.2\%) indicated they did not have the necessary clinical knowledge to manage and treat HIV patients; the same number believed they could be ready to manage and treat HIV patients with some training (Tables 3 and 4). The majority (103, 59.0\%) agreed PCPs should manage and treat HIV patients, and most $(125,71.0 \%)$ believed helping was important to alleviate the HIV provider shortage. The majority $(94,53.4 \%)$ were not interested in attending salaried, HIV-specialist fellowship training but were interested in managing and treating HIV patients if time permitted $(110,62.5 \%)$. Almost half $(84$, 47.7\%) were interested in treating HIV patients if they were better compensated (Table 4), and many (83, 47.2\%) believed PCPs were the best solution for the HIV provider shortage. 
Table 1 Demographic Characteristics of Primary Care Clinicians Who Completed the Survey $(N=347)$

\begin{tabular}{|c|c|}
\hline Demographic Characteristic & $\begin{array}{l}\text { No }(\%) \text { or } N \\
\text { (SD) }\end{array}$ \\
\hline \multicolumn{2}{|l|}{ Designation } \\
\hline Physician & $172(49.6)$ \\
\hline Resident physician & $42(12.1)$ \\
\hline Physician assistant & $67(19.3)$ \\
\hline Nurse practitioner & $66(19.0)$ \\
\hline \multicolumn{2}{|l|}{ Extent of practice } \\
\hline Full-time & $258(74.4)$ \\
\hline Part-time & $54(15.6)$ \\
\hline Locum/per diem & $12(3.5)$ \\
\hline Other & $23(6.6)$ \\
\hline \multicolumn{2}{|l|}{ Gender } \\
\hline Male & $142(40.9)$ \\
\hline Female & $202(58.5)$ \\
\hline Transgender & $2(0.6)$ \\
\hline Mean age & $43 \cdot 2(11.9)$ \\
\hline Mean number of hours weekly & $39.3(15.5)$ \\
\hline Mean number of years in practice & $12 \cdot 2(10.8)$ \\
\hline \multicolumn{2}{|l|}{ Plan to retire } \\
\hline Within 2 years & $8(2.3)$ \\
\hline Within $2-5$ years & $16(4.6)$ \\
\hline Within 5-10 years & $54(15.6)$ \\
\hline More than 10 years & $160(46.1)$ \\
\hline No plan to retire & $109(31.4)$ \\
\hline \multicolumn{2}{|l|}{ Race/Ethnicity } \\
\hline White & $203(58.5)$ \\
\hline Hispanic and Latino & $42(12.1)$ \\
\hline Black or African American & $25(7.2)$ \\
\hline Asian & $42(12.1)$ \\
\hline Native Hawaiian and Other Pacific Islander & $1(0.3)$ \\
\hline Other & $34(9.8)$ \\
\hline \multicolumn{2}{|l|}{ Practice state } \\
\hline California & $101(29.1)$ \\
\hline Colorado & $22(6.3)$ \\
\hline Florida & $16(4.6)$ \\
\hline Illinois & $14(4.0)$ \\
\hline Nebraska & $15(4.3)$ \\
\hline New York & $20(5.8)$ \\
\hline North Carolina & $10(2.9)$ \\
\hline Pennsylvania & $14(4.0)$ \\
\hline Texas & $17(4.9)$ \\
\hline Washington & $11(3.2)$ \\
\hline Remaining 37 states & $107(30.9)$ \\
\hline
\end{tabular}

Table 1 Demographic Characteristics of Primary Care Clinicians Who Completed the Survey ( $N=347)$ (Continued)

\begin{tabular}{|c|c|}
\hline Demographic Characteristic & $\begin{array}{l}\text { No (\%) or Mean } \\
\text { (SD) }\end{array}$ \\
\hline \multicolumn{2}{|l|}{ Practice location } \\
\hline Urban & $167(48.1)$ \\
\hline Suburban & $91(26.2)$ \\
\hline Rural & $89(25.7)$ \\
\hline \multicolumn{2}{|l|}{ Practice setting } \\
\hline Hospital & $39(11.2)$ \\
\hline Solo practice & $34(9.8)$ \\
\hline Group practice & $112(32.3)$ \\
\hline $\begin{array}{l}\text { Community care (rural health/federally } \\
\text { qualified) }\end{array}$ & $130(37.5)$ \\
\hline Other & $32(9.2)$ \\
\hline \multicolumn{2}{|l|}{ Average number of patients treated in a day } \\
\hline 9 or fewer & $48(13.8)$ \\
\hline $10-19$ & $180(51.9)$ \\
\hline $20-29$ & $104(30.0)$ \\
\hline More than 30 & $15(4.3)$ \\
\hline \multicolumn{2}{|l|}{ Currently treat HIV patients } \\
\hline Yes & $171(49.3)$ \\
\hline No & $176(50.7)$ \\
\hline \multicolumn{2}{|l|}{ Certified HIV specialist } \\
\hline Yes & $80(23.0)$ \\
\hline No & $224(64.6)$ \\
\hline No, but considering becoming an HIV specialist & $42(12.1)$ \\
\hline Yes, but considering quitting the specialty & $1(0.3)$ \\
\hline
\end{tabular}

\section{Responses from PAs and NPs}

One hundred thirty-three PAs and NPs participated in the study. Seventy (52.6\%) believed they could be ready to manage HIV patients with some training (Tables 3 and 4). Most $(107,80.5 \%)$ believed helping was important to alleviate the HIV provider shortage. An equal number of PAs and NPs $(47,35.3 \%)$ were interested or not interested in attending salaried, HIV-specialist fellowship training.

\section{Comparison analysis between groups}

One hundred seventy-one PCPs reported currently treating HIV patients, and 176 reported they did not. PCPs practicing HIV medicine were more likely than those not practicing HIV medicine to agree that PCPs should help with the HIV provider shortage (Fig. 1) $(U=10,384$, $p<0.001)$ and that PCPs are the best solution to the HIV provider shortage (Fig. 2) $(U=10,294, p<0.001)$.

\section{Discussion}

We investigated whether PCPs were prepared to manage and treat patients with HIV. Overall, most respondents 
believed that PCPs should start managing and treating patients with HIV. Further, PCPs currently treating HIV patients were significantly more likely to agree that PCPs should take care of HIV patients than PCPs who were not.

There are 3101 PCPs in the United States who provide HIV care and consult with 10 or more HIV patients daily [18]. According to the Agency for Healthcare Research and Quality [19], there are currently 294,834 PCPs in the United States. Only a small percentage of PCPs manage and treat HIV patients; therefore, the responses of PCPs in the current study who did not treat and manage HIV patients are important, because they more representative of the overall primary care workforce.

For instance, our findings suggest PCPs should be more aware of some aspects of the HIV epidemic. Further, results suggest PCPs have concerns about provider salary, HIV provider training, and struggles with time limitations. Although PCPs had adequate knowledge about HIV and its basic elements, almost half did not know or were uncertain how many new HIV infections occur annually in the United States. Therefore, clinicians should be better educated about HIV to increase awareness of the problem.

In the current study, only $12 \%$ of PCPs treating HIV patients agreed they were compensated sufficiently for HIV care. This result suggested most PCPs involved with HIV medicine were unsatisfied with their salary. Moreover, $48 \%$ of PCPs who were not treating HIV patients indicated they would consider treating HIV patients if they were compensated better. Weddle and Hauschild's [7] findings support our finding that HIV clinicians are not compensated sufficiently. Traditionally, patients with HIV were treated and managed by infectious disease or HIV specialists. In contrast, when PCPs treat and manage these patients they manage, not only HIV, but also other chronic medical conditions; consequently, these patients receive comprehensive care, which can be complex and time consuming for providers. Taken together, our findings suggest PCPs expect higher compensation when managing HIV patients. Barakat [20] found patients are happy with this integrated model confirming they prefer this model, because they can receive comprehensive care (i.e., primary and HIV care) from one clinician [20]. This finding that patients with HIV prefer seeing PCPs, who provide primary and HIV care is important for PCPs as it may encourage them to consider getting more involved with HIV medicine.

Most PCPs in the current study indicated they lacked knowledge to treat and manage HIV patients, but most believed that they would be able to treat and manage HIV patients with some additional training. Weddle and Hauschild [7] found that PCPs were not qualified to manage and treat HIV patients. Gatty [6] proposed an HIV fellowship to increase the number of HIV providers. However, most PCPs in the current study did not like the idea of doing a lengthy HIV fellowship. As such, only a handful of US clinicians may be open to the idea of doing an HIV fellowship and becoming an HIV specialist. These results suggest PCPs may be interested in infrequent, but not long-term HIV-related training, such as HIV fellowships. The AIDS Education and Training Centers (AETC) are a network of eight regional training centers that provide HIV education [21]. Increasing the HIV workforce through proper training along the HIV care continuum is a priority for AETC [22]. Collaborating with the AETC to implement not only infrequent but also short-term HIV fellowships for PCPs may encourage them to attend HIV related training. Waldura [23] confirmed that PCPs who had access for HIV medical advice through a phone line (i.e., Warmline) reported that they are more confident with HIV care and are less dependent on referring patients to HIV specialists. These Warmline professionals are readily available for providers in regard to HIV related questions; particularly when dealing with complex cases. These phone consultations would also be useful for PCPs in rural locations. Considering the above findings, the AETC promotes more technological assistance to providers, who are involved with HIV medicine [22]. Apart from AETC, there are other clinicians' Warmline available in the United States offered by other agencies like the Centers for Disease Control and Prevention (CDC) [24]. Therefore, educating PCPs about these resources and helpful services may encourage them to get involved with HIV medicine.

The Health Resources and Services Administration's (HRSA) Ryan White HIV/AIDS program Part F Special

Table 2 Primary Care Clinicians' Knowledge About Management and Treatment of HIV

\begin{tabular}{|c|c|c|c|}
\hline \multirow[t]{2}{*}{ Survey Question } & \multicolumn{3}{|l|}{ No. (\%) } \\
\hline & Yes & No & Uncertain \\
\hline There is an HIV provider shortage in the United States & $257(74.1)$ & $12(3.5)$ & $78(22.5)$ \\
\hline Because of antiretroviral therapy, HIV patients live longer now than in previous years & $346(99.7)$ & 0 & $1(0.3)$ \\
\hline HIV is a chronic disease & $340(98.0)$ & $5(1.4)$ & $2(0.6)$ \\
\hline Over the past 10 years, HIV treatments have advanced greatly & $332(95.7)$ & $4(1.2)$ & $11(3.2)$ \\
\hline Every year there are about 50,000 new HIV patients & $186(53.6)$ & $8(2.3)$ & $153(44.1)$ \\
\hline
\end{tabular}


Table 3 Primary Care Clinicians' Beliefs about Management and Treatment of HIV

\begin{tabular}{|c|c|c|c|}
\hline \multirow[t]{2}{*}{ Survey Question } & \multicolumn{3}{|l|}{ No. (\%) } \\
\hline & Agree & Uncertain & Disagree \\
\hline \multicolumn{4}{|c|}{ I have the necessary clinical knowledge to manage and treat HIV patients } \\
\hline All PCPs & $143(41.2)$ & $52(15.0)$ & $152(43.8)$ \\
\hline Only PCPs involved with HIV medicine & $90(70.2)$ & $19(11.1)$ & $32(18.7)$ \\
\hline Only PCPs not involved with HIV medicine & $23(13.0)$ & $33(18.8)$ & $120(68.2)$ \\
\hline Only PAs and NPs & $44(33.1)$ & $19(14.3)$ & $70(52.6)$ \\
\hline \multicolumn{4}{|c|}{ I have the necessary education to manage and treat HIV patients } \\
\hline All PCPs & $161(46.4)$ & $48(13.8)$ & $138(39.8)$ \\
\hline Only PCPs involved with HIV medicine & $125(74.1)$ & $15(8.8)$ & $31(18.1)$ \\
\hline Only PCPs not involved with HIV medicine & $36(20.4)$ & $33(18.8)$ & $107(60.8)$ \\
\hline Only PAs and NPs & $53(39.8)$ & $17(12.8)$ & $63(47.4)$ \\
\hline \multicolumn{4}{|c|}{ With some training, I will be ready to take care of HIV patients } \\
\hline All PCPs & $207(59.7)$ & $118(34.0)$ & $22(6.3)$ \\
\hline Only PCPs involved with HIV medicine & $87(50.8)$ & $80(46.8)$ & $4(2.4)$ \\
\hline Only PCPs not involved with HIV medicine & $120(68.2)$ & $38(21.6)$ & $18(10.2)$ \\
\hline Only PAs and NPs & $70(52.6)$ & $55(41.4)$ & $8(6.0)$ \\
\hline \multicolumn{4}{|c|}{ Primary care clinicians should take care of HIV patients } \\
\hline All PCPs & $245(70.6)$ & $60(17.3)$ & $42(12.1)$ \\
\hline Only PCPs involved with HIV medicine & $142(83.0)$ & $17(9.9)$ & $12(7.0)$ \\
\hline Only PCPs not involved with HIV medicine & $103(58.5)$ & $43(24.4)$ & $30(17.1)$ \\
\hline Only PAs and NPs & $70(52.6)$ & $37(27.8)$ & $26(19.5)$ \\
\hline \multicolumn{4}{|c|}{ The number of new HIV cases is stable in the United States; therefore, there is no need to worry about HIV anymore } \\
\hline All PCPs & $1(0.3)$ & $31(8.9)$ & $315(90.8)$ \\
\hline Only PCPs involved with HIV medicine & $1(0.6)$ & $4(2.3)$ & $166(97.0)$ \\
\hline Only PCPs not involved with HIV medicine & $0(0.0)$ & $27(15.3)$ & $149(84.7)$ \\
\hline Only PAs and NPs & $0(0.0)$ & $13(9.8)$ & $120(90.2)$ \\
\hline \multicolumn{4}{|c|}{ Planning to resolve the HIV provider shortage is a priority of the healthcare agencies at this time } \\
\hline All PCPs & $109(22.4)$ & $119(34.3)$ & $119(34.3)$ \\
\hline Only PCPs involved with HIV medicine & $57(33.3)$ & $45(26.3)$ & $69(40.3)$ \\
\hline Only PCPs not involved with HIV medicine & $52(29.5)$ & $74(42.0)$ & $50(28.5)$ \\
\hline Only PAs and NPs & $44(33.1)$ & $44(33.1)$ & $45(33.8)$ \\
\hline \multicolumn{4}{|c|}{ When treating HIV patients, clinicians are compensated sufficiently } \\
\hline All PCPs & $26(7.5)$ & $183(52.7)$ & $138(39.8)$ \\
\hline Only PCPs involved with HIV medicine & $20(11.7)$ & $66(38.6)$ & $85(49.7)$ \\
\hline Only PCPs not involved with HIV medicine & $6(3.4)$ & $117(66.5)$ & $53(30.1)$ \\
\hline Only PAs and NPs & $7(5.3)$ & 77 (57.9) & $49(36.8)$ \\
\hline
\end{tabular}

$N=347$ for all PCPs, $n=171$ for only PCPs involved with HIV medicine, $n=176$ for only PCPs not involved with HIV medicine, and $n=133$ for only PAs and NPs. Abbreviations: NP Nurse practitioner, PA Physician assistant, PCP Primary care provider (includes physicians, PAs, and NPs)

Projects of National Significance (SPNS) Program supports the development of innovative models of HIV care and treatment, when necessary [25]. One of the SPNS initiatives includes system-level workforce capacity building for integrating HIV primary care in community health care settings. With this approach, the Program investigates how to respond to the changing health care landscape marked by shortages of HIV primary care physicians and increasing demand for access to quality HIV services [25]. Therefore, recognizing successfully implemented projects under SPNS and replicating them at more health care settings, and then educating clinicians about such available services may encourage them to become more involved with HIV medicine. According 
Table 4 Primary Care Clinicians' Attitudes About Management and Treatment of HIV

\begin{tabular}{|c|c|c|c|}
\hline \multirow[t]{2}{*}{ Survey Question } & \multicolumn{3}{|l|}{ No. (\%) } \\
\hline & Agree & Uncertain & Disagree \\
\hline \multicolumn{4}{|c|}{ I worry about the projected HIV workforce shortage } \\
\hline All PCPs & $193(55.6)$ & $93(26.8)$ & $61(17.6)$ \\
\hline Only PCPs involved with HIV medicine & $121(70.8)$ & $32(18.7)$ & $18(10.5)$ \\
\hline Only PCPs not involved with HIV medicine & $72(40.9)$ & $61(34.7)$ & $43(24.4)$ \\
\hline Only PAs and NPs & $67(50.4)$ & $41(30.8)$ & $25(18.8)$ \\
\hline \multicolumn{4}{|c|}{ There are enough other health care crises to worry about than HIV } \\
\hline All PCPs & $51(14.7)$ & $78(22.5)$ & $218(62.8)$ \\
\hline Only PCPs involved with HIV medicine & $21(12.3)$ & $31(18.1)$ & $119(69.5)$ \\
\hline Only PCPs not involved with HIV medicine & $30(17.0)$ & $47(26.7)$ & $99(56.3)$ \\
\hline Only PAs and NPs & $15(11.3)$ & $31(23.3)$ & $87(65.4)$ \\
\hline \multicolumn{4}{|c|}{ I would like to take care of HIV patients while providing primary care } \\
\hline All PCPs & $239(68.9)$ & $68(19.6)$ & $40(11.5)$ \\
\hline Only PCPs involved with HIV medicine & $155(90.6)$ & $11(6.4)$ & $5(3.0)$ \\
\hline Only PCPs not involved with HIV medicine & $84(47.7)$ & $57(32.4)$ & $35(19.9)$ \\
\hline Only PAs and NPs & $80(60.2)$ & $33(24.8)$ & $20(15.0)$ \\
\hline \multicolumn{4}{|c|}{ If a primary care clinician is the answer to alleviate HIV provider shortage, I should help out } \\
\hline All PCPs & $291(83.8)$ & $41(11.8)$ & $15(4.4)$ \\
\hline Only PCPs involved with HIV medicine & $136(97.0)$ & $3(1.8)$ & $2(1.2)$ \\
\hline Only PCPs not involved with HIV medicine & $125(71.0)$ & $38(21.6)$ & $13(7.4)$ \\
\hline Only PAs and NPs & $107(80.5)$ & $20(15.0)$ & $6(4.5)$ \\
\hline \multicolumn{4}{|c|}{ I would like to attend 1-2 years HIV salaried specialist fellowship training, if available } \\
\hline All PCPs & $87(25.1)$ & $101(29.1)$ & $159(45.8)$ \\
\hline Only PCPs involved with HIV medicine & $46(26.9)$ & $60(35.1)$ & $65(35.0)$ \\
\hline Only PCPs not involved with HIV medicine & $41(23.3)$ & $41(23.3)$ & $94(53.4)$ \\
\hline Only PAs and NPs & $47(35.3)$ & $39(29.3)$ & $47(35.3)$ \\
\hline \multicolumn{4}{|c|}{ I will consider taking care of HIV patients if I have enough time } \\
\hline All PCPs & $209(60.2)$ & $107(30.9)$ & $31(8.9)$ \\
\hline Only PCPs involved with HIV medicine & $99(57.8)$ & $66(38.6)$ & $6(3.5)$ \\
\hline Only PCPs not involved with HIV medicine & $110(62.5)$ & $41(23.3)$ & $25(14.2)$ \\
\hline Only PAs and NPs & $77(57.9)$ & $44(33.1)$ & $12(9.0)$ \\
\hline \multicolumn{4}{|c|}{ I will consider taking care of HIV patients if I am compensated better } \\
\hline All PCPs & $179(51.6)$ & $92(26.5)$ & $76(21.9)$ \\
\hline Only PCPs involved with HIV medicine & $95(55.6)$ & $35(20.5)$ & $41(20.9)$ \\
\hline Only PCPs not involved with HIV medicine & $84(47.7)$ & $57(32.4)$ & $35(19.9)$ \\
\hline Only PAs and NPs & $62(46.6)$ & $38(28.6)$ & $33(24.8)$ \\
\hline \multicolumn{4}{|l|}{ I am not interested in HIV medicine } \\
\hline All PCPs & $43(12.4)$ & $40(11.5)$ & $264(76.1)$ \\
\hline Only PCPs involved with HIV medicine & $5(3.0)$ & $6(3.5)$ & $160(93.6)$ \\
\hline Only PCPs not involved with HIV medicine & $38(21.6)$ & $34(19.3)$ & $104(59.1)$ \\
\hline Only PAs and NPs & $20(15.0)$ & $19(14.3)$ & $94(70.7)$ \\
\hline \multicolumn{4}{|c|}{ Primary care providers are the best solution to the HIV provider shortage } \\
\hline All PCPs & $206(59.3)$ & $113(32.6)$ & $28(8.1)$ \\
\hline Only PCPs involved with HIV medicine & $123(71.9)$ & $39(22.8)$ & $9(5.3)$ \\
\hline
\end{tabular}


Table 4 Primary Care Clinicians' Attitudes About Management and Treatment of HIV (Continued)

\begin{tabular}{llll}
\hline Survey Question & No. $(\%)$ & & \\
\cline { 2 - 4 } & Agree & Uncertain & Disagree \\
\hline Only PCPs not involved with HIV medicine & $83(47.2)$ & $50(37.6)$ & $19(10.8)$ \\
Only PAs and NPs & $65(48.9)$ & $18(13.5)$
\end{tabular}

$N=347$ for all PCPs, $n=171$ for only PCPs involved with HIV medicine, $n=176$ for only PCPs not involved with HIV medicine, and $n=133$ for only PAs and NPs Abbreviations: NP Nurse practitioner, PA Physician assistant, $P C P$ Primary care provider (includes physicians, PAs, and NPs)

to HRSA's Ryan White HIV/AIDS report, the Program served more than 551,000 people living with HIV - that is greater than half of all HIV patients in the United States [25]. The Program serves insured, uninsured, low-income, and underserved populations. Also, the Program covers medical services within HIV clinics and other health care settings. Patients are eligible for services provided by social workers, pharmacists, psychiatrists, and other providers. In 2016, about 63\% of Program patients were living at or below $100 \%$ of the federal poverty level [25]. An opportunity to join an interdisciplinary team of providers through involvement with the Ryan White HIV/AIDS Program may motivate PCPs to consider engaging in HIV medicine. For example, a PCP can refer patients in need of behavioral health counseling to a psychiatrist and/or mental health counselor through the Ryan White HIV/AIDS Program, and all or most of the cost of these services would be covered [26]. Educating PCPs about these available services is vital to reduce perceived barriers towards and increase motivation for involvement in HIV medicine, thereby, increasing access to care for HIV infected patients.

Of PCPs not currently involved with HIV patients, $63 \%$ stated they would consider managing and treating HIV patients if time permitted. Bendix et al. [16] found that PCPs were burned out by their existing workload. Our findings support Bendix et al.'s, because our PCPs did not feel they had enough time. Overall, these finding suggest that a heavy workload is a barrier to different or additional responsibilities.

Research $[12,13]$ suggests that HIV clinician teams of PCPs achieve similar outcomes in the management of HIV patients when compared with physicians alone. In the current study, $81 \%$ of surveyed PAs and Family NPs believed they could help alleviate the HIV provider shortage by managing and treating these patients. Further, 35\% were interested in attending salaried HIV specialist fellowship training. Given these results, a practical solution for addressing the HIV provider shortage may include reaching out to PAs and NPs and encouraging them to be involved with HIV medicine.

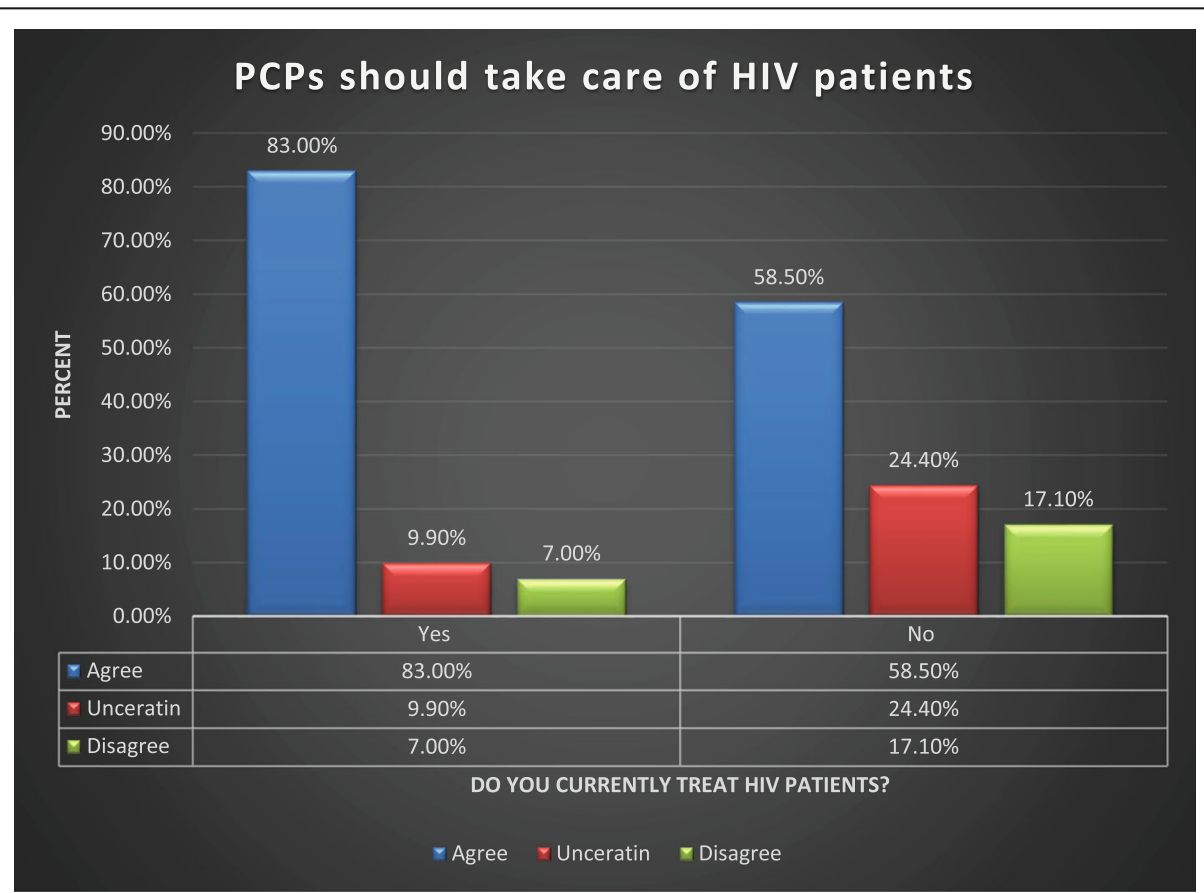

Fig. 1 Comparison analysis between groups: PCP's who currently practice HIV medicine vs. PCP's who currently do not practice HIV medicine 


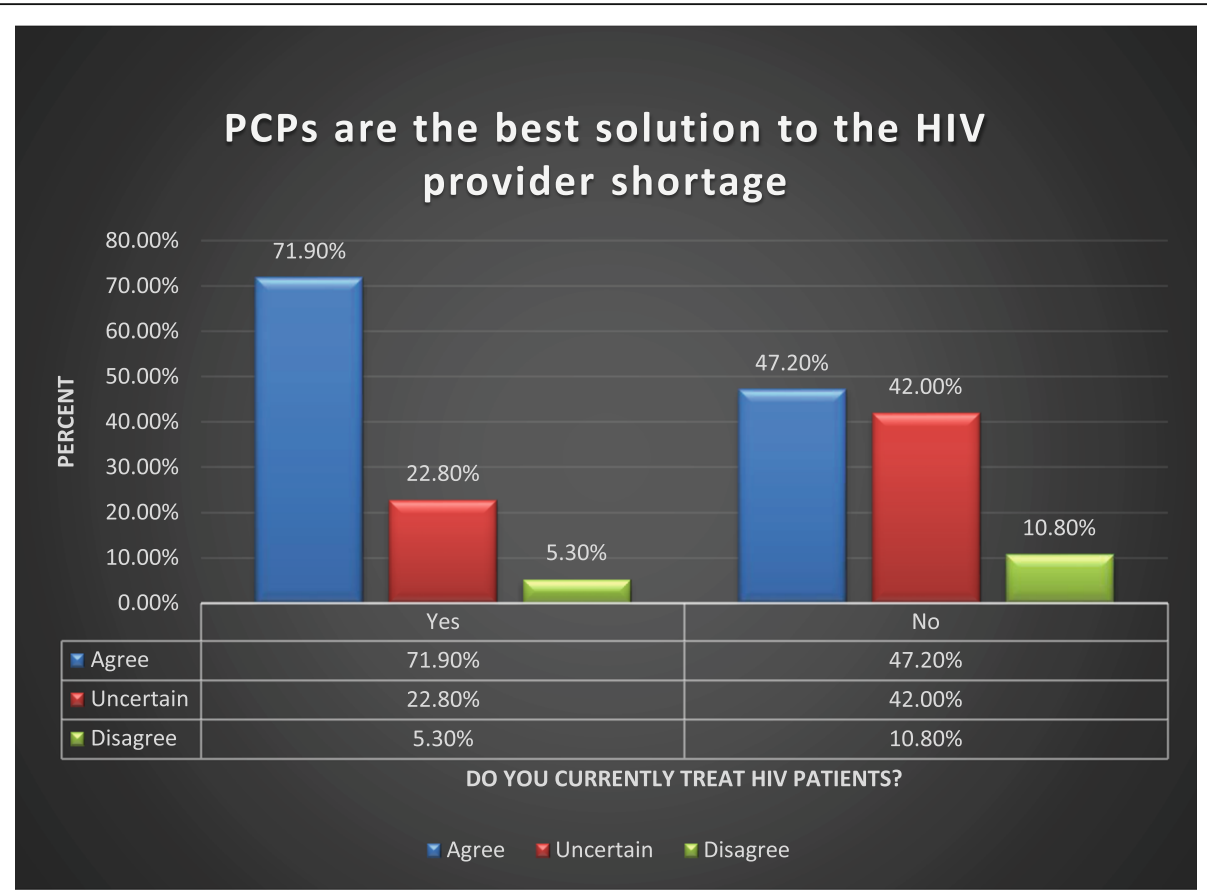

Fig. 2 Comparison analysis between groups: PCP's who currently practice HIV medicine vs. PCP's who currently do not practice HIV medicine

AIDS United is a nonprofit organization, which is strategizing to end the HIV epidemic (i.e., Getting to Zero) in the United States by 2025 [27]. Under the Getting to Zero initiative, the organization focuses on workforce recruitment and retention. AIDS united has halted funding elimination of SPNS and AETC in order to continue their efforts to alleviate the workforce provider shortage [28]. There are many resources available at these entities and programs (e.g., AIDS United, SPNS, AETC, CDC, and AAHIVM) for providers who are considering entering in to HIV medicine. Therefore, educating PCPs about such available services may encourage them to get involved with HIV medicine. To achieve Getting to Zero by 2025, the entities and aforementioned programs should continue their efforts to alleviate the HIV provider shortage.

The current study has some limitations. Although the percentage of PCPs in the United States practicing HIV medicine is small, many PCPs who were involved with HIV medicine completed our survey likely because of the survey distribution method. Therefore, our findings may not be representative of or generalizable to the overall population. To address this limitation in our analysis, responses from PCPs not involved with HIV medicine were compared against responses from all participants. Another limitation is the way the survey was distributed. One of our methods of distribution involved circulating the survey within US primary care residency programs. Some programs participated in the study and circulated the questionnaire within their systems. However, the number of surveys circulated in those systems is unknown, so a response rate could not be calculated. Participation bias may also be a limitation. Because completion of the survey was voluntary, only those PCPs already interested in HIV medicine may have responded. Another limitation was there was no survey question to identify if survey respondents were serving private or public insurance, which would have been an appropriate way to determine if PCPs were more involved with HIV care if patients had private versus public insurance due to different pay scales. Also, questions related to HIV-related stigma were not included. Geter et al. concluded "providers with limited recent HIVstigma training were more likely to exhibit stigmatizing behaviors toward patients. Developing provider-centered stigma-reduction interventions may help advance national HIV prevention and care goals." [29] A question about PCPs HIV-related stigma and their decision or willingness to care for and treat people living with HIV would have been useful for the current study. Further research is needed to determine if there is a correlation between PCPs HIV-related stigma and willingness to manage HIV infected patients, which understanding could help guide efforts to reduce barriers towards PCP involvement in HIV medicine. Additional research is also helpful to explore PCPs perceived knowledge, beliefs, and attitudes about their readiness to manage and treat HIV patients in states with high burden of HIV versus states with low burden of HIV in the United States. According to CDC, HIV diagnoses are unequally distributed regionally in the U.S. [1] In 2018, 15.7\% cases were in the 
South; $12.7 \%$ were in the US dependent areas; $10 \%$ in the Northeast; $9.3 \%$ in the West; and 7.2\% in the Midwest [1]. Such research will help determining if adequate number of PCPs are ready and/or willing to consider managing patients with HIV in those areas with higher prevalence.

While many PCPs of the current study were interested in managing and treating HIV patients, they faced critical barriers to doing so, such as lack of knowledge of HIV medicine, lack of time, and insufficient reimbursement. Further, although most PCPs understood the need for additional training to treat and manage HIV patients, our results suggested an HIV fellowship to provide training was not practical for most respondents. Therefore, short, regular training sessions to manage and treat HIV patients (i.e., a few hours weekly) may be the best solution, but these sessions should not impinge on routine clinical obligations. Another solution may be providing PCPs opportunities to participate in basic HIV training with the expectation that they will be able to manage and treat stable HIV patients while referring complex HIV patients to an HIV or infectious disease specialist. Because lack of time will continue to be a problem for PCPs, perhaps those who want to manage and treat HIV patients should have a lighter schedule, allowing them to give more time to HIV patients. Finally, steps should be taken to ensure that HIV providers are better compensated.

\section{Conclusion}

In the current study, most PCPs agreed that they could be the solution to the HIV provider shortage and were interested in managing and treating HIV patients. However, our results suggest most PCPs in the United States are not involved with HIV medicine. Therefore, it seems the HIV provider shortage will continue. To alleviate this shortage and improve HIV patient care, PCPs should be offered additional training, decreased workloads, and increased compensation to better treat and manage HIV patients.

\section{Supplementary information}

Supplementary information accompanies this paper at https://doi.org/10 1186/s12875-020-01198-7.

Additional file 1: Appendix. Survey Instrument.

\footnotetext{
Abbreviations

PCP: Primary Care Provider; HIV: Human Immunodeficiency Virus; PA: Physician Assistant; NP: Nurse Practitioner; US: United States; AIDS: Acquired Immune Deficiency Syndrome; ART: Antiretroviral therapy; AAHIVM: American Academy of HIV Medicine; IBM: International Business Machines; SPSS: Statistical Package for the Social Science; SD: Standard Deviation; AETC: AIDS Education and Training Centers; CDC: Centers for Disease Control and Prevention; HRSA: Health Resources and Services Administration; SPNS: Special Projects of National Significance; CA: California; NY: New York; A.T.: Andrew Taylor (Acknowledgment); UC: University of California (Acknowledgment); PA-C: Physician Assistant Certified (Authors' information)
}

\section{Acknowledgements}

The authors thank Deborah Goggin, MA (A.T. Still University), Jeffrey Elias PhD (UC Davis) for editorial assistance, all the PCPs who participated in this study, and the colleagues, who evaluated the survey questions and provided constructive feedback to improve the validity.

\section{Authors' contributions}

SW and JA had full access to all data in the study and take responsibility for the integrity of data and the accuracy of the data analysis. Study concept and design: SW. Acquisition, analysis, or interpretation of data: SW and JA. Drafting of the manuscript: SW. Critical revision of the manuscript for important intellectual content: JA. Statistical analysis: SW and JA.

Administrative, technical, or material support: SW. Study supervision: SW and JA. The authors read and approved the final manuscript.

\section{Authors' information}

SW is a principal faculty at MSPA education, Stanford School of Medicine, family medicine PA-C, and HIV specialist. His clinical interests include primary care medicine, HIV medicine, and global health. Primarily, his focus is on primary care and HIV-workforce shortage and HIV testing and management. SW was awarded the HIV and AIDS fellowship research at the American Conference for the Treatment for HIV in 2014. Presently, SW is investigating if the HIV provider shortage is a threat for the U.S. health care system.

\section{Funding}

None.

\section{Availability of data and materials}

The dataset used and analyzed during the current study is available from the corresponding author on reasonable request.

\section{Ethics approval and consent to participate}

A.T. Still University was the institutional review board for the study. Ethical approval was not necessary. The local institutional review board considered the current study exempt from review.

\section{Consent for publication}

Not applicable.

\section{Competing interests}

The authors declare that there are no competing interests.

Received: 24 October 2018 Accepted: 17 June 2020

Published online: 01 July 2020

\section{References}

1. Centers for Disease Control \& Prevention. HIV in the United States and dependent areas. https://www.cdc.gov/hiv/statistics/overview/ataglance. html. Accessed 27 May 2020.

2. Centers for Disease Control and Prevention. Diagnoses of HIV infection in the United States and dependent areas, 2013. HIV Surveill Rep. 2015;25:1-82 https://www.cdc.gov/hiv/pdf/library/reports/surveillance/cdc-hivsurveillance-report-2013-vol-25.pdf. Accessed 15 Feb 2018.

3. U.S. Department of Health and Human Services. HIV treatments: the basics. https://aidsinfo.nih.gov/education-materials/fact-sheets/21/51/hivtreatment\%2D\%2Dthe-basics. Accessed 15 Feb 2018.

4. Gatty B. Who will care for them? HIV Specialist. 2009;1:8-15 https:/aahivm. org/wp-content/uploads/2017/03/HIVSpecialistMagazineSpring2009.pdf. Accessed 15 Mar 2018

5. Sweet DE. HIV workforce and new models for HIV care: an expert's perspective. https://www.medscape.org/viewarticle/776146. (Accessed 15 Feb 2018.).

6. Gatty B. The HIV workforce: a looming crisis. HIV Specialist. 2016;8:12-7 https://aahivm.org/wp-content/uploads/2017/03/FINAL-MARCH-2016.pdf. Accessed 15 Mar 2018

7. Weddle A, Hauschild B. HIV medical provider experiences: results of a survey of Ryan White Part C program http://www.hivma.org/uploadedFiles/HIVMA/ Policy_and_Advocacy/Policy_Priorities/HIV_Medical_Workforce/Resources/ Ryan\%20White\%20Part\%20C\%20Survey\%2010M\%209\%2026\%2010.pdf. Accessed 15 Feb 2018. 
8. Mathematica Policy Research. Gap in supply of HIV clinicians expected to increase. https://www.mathematica-mpr.com/news/hiv-specialist Accessed 28 Apr 2019.

9. Vanemti S, Johnson LB. One solution to looming physician shortage. HIV Specialist. 2016:19-20 http://www.natap.org/2016/HIV/FINALMARCH\%202 016.pdf. Accessed 28 Apr 2019.

10. Gallant JE, Adimora AA, Carmichael JK, et al. Essential components of effective HIV care: a policy paper of the HIV medicine Association of the Infectious Diseases Society of America and the Ryan white medical providers coalition. Clin Infect Dis. 2011;53:1043-50.

11. Institute of Medicine. HIV screening and access to care: health care system capacity for increased HIV testing and provision of care. Washington, DC: The National Academies Press; 2011.

12. HIV Medicine Association. The role of advanced practice registered nurses and physician assistants in HIV care policy statement. http://www.hivma. org/uploadedFiles/HIVMA/Policy_and_Advocacy/APRN_PA_Final_Statement. pdf. Accessed 15 Feb 2018.

13. Wilson IB, Landon BE, Hirschhom LR, et al. Quality of HIV care provided by nurse practitioners, physician assistants, and physicians. Ann Intern Med. 2005;143:729-36.

14. Romanelli F, Matheny SC. HIV infection: the role of primary care. Am Fam Physician. 2009;80:946-52.

15. Association of American Medical Colleges. The Complexities of Physician Supply and Demand: Projections from 2013 to 2025. https://www.aamc.org/ download/426242/data/. Accessed 15 Mar 2018.

16. Bendix J, Verdon DR, Ritchie A, Marbury D, Mazzolini C. Top 10 challenges facing physicians in 2014. Med Econ. 2013; http://medicaleconomics. modernmedicine.com/medical-economics/content/tags/affordable-care-act/ top-10-challenges-facing-physicians-2014. Accessed 15 Feb 2018.

17. HIV.gov. National HIV/AIDS strategy: updated to 2020. https://www.hiv.gov/ federal-response/national-hiv-aids-strategy/nhas-update. (Accessed 15 Feb 2018).

18. Gilman B, Hogan P, Trent-Adams S, Cheever L, Bouchery E, Negrusa S. The HIV clinician workforce in the United States: supply and demand projections from 2010 to 2015. HIV Specialist. 2016;8:2-9.

19. Agency for Healthcare Research and Quality. The distribution of the U.S primary care workforce: primary care workforce facts and stats, No. 3. https://www.ahrq.gov/research/findings/factsheets/primary/pcwork3/index. html. Accessed 15 Feb 2018.

20. Barakat LA, Dunne DW, Tetrault JM, et al. The changing face of HIV care: expanding HIV training in an internal medicine residency program. Acad Med. 2018:93(11):1673-8. https://doi.org/10.1097/ACM.0000000000002317.

21. Aids Education and Training Center. About the AIDS education and training center program. https://aidsetc.org/about. (Accessed 28 Apr 2019.).

22. Health Resources and Service Administration. AIDS Education and training Center annual data report 2014. https:/hab.hrsa.gov/sites/default/files/hab/ data/datareports/2014aetcdatareport.pdf. Accessed 28 Apr 2019.

23. Waldura JF, Neff S, Zehlendorf C, Goldschmidt RH. Teleconsultation improves primary care clinicians' confidence about caring for HIV. J Gen Intern Med. 2013;28(6):793-800. https://doi.org/10.1007/s11606-013-2332-5 Epub 2013 Feb 1.

24. Centers for Disease Control and Prevention. Hotlines and referrals. https:// www.cdc.gov/hiv/library/hotlines.html. Accessed 28 Apr 2019.

25. US Department of Health and Human Service. Program overview. https:// hab.hrsa.gov/sites/default/files/hab/Publications/factsheets/programfactsheet-program-overview.pdf. Accessed 28 Apr 2019

26. Health Resources and Service Administration. Part A: Grants to eligible metropolitan and transitional areas. https://hab.hrsa.gov/about-nyan-white-hivaids-program/part-agrants-emerging-metro-transitional-areas. Accessed 2 May 2019.

27. Aids United. Ending the HIV epidemic in the US. https://www.aidsunited. org. Accessed 28 Apr 2019.

28. Aids United. Leading for impact, 2017 annual report. https://www. aidsunited.org/data/files/Site_18/About/au_annual_report\%202017_ FINAL_11.26.18.pdf. Accessed 28 Apr 2019.

29. Geter A, Herron AR. HIV-Related stigma by healthcare providers in the United States: A systematic review. AIDS Patient Care STDS. 2018;32(10). https://doi.org/10.1089/apc.2018.0114

\section{Publisher's Note}

Springer Nature remains neutral with regard to jurisdictional claims in published maps and institutional affiliations.

Ready to submit your research? Choose BMC and benefit from:

- fast, convenient online submission

- thorough peer review by experienced researchers in your field

- rapid publication on acceptance

- support for research data, including large and complex data types

- gold Open Access which fosters wider collaboration and increased citations

- maximum visibility for your research: over $100 \mathrm{M}$ website views per year

At BMC, research is always in progress.

Learn more biomedcentral.com/submissions 